\title{
Arte, afeto fundamental e transcendência teológica em Heidegger
}

Chiara Pasqualin - Universidade de São Paulo

A publicação póstuma da obra de Heidegger intitulada Beiträge zur Philosophie ${ }^{1}$ tem oferecido uma preciosa chave de acesso para ler, sob uma nova luz, toda a sua produção posterior ao período da Ontologia Fundamental. As Contribuições à filosofia constituem a obra fundadora da segunda via da reflexão heideggeriana, aquela da história do ser, na medida em que lhe dão sua primeira e mais ampla configuração, delineando sua estrutura conceitual. Os Beiträge zur Philosophie lançam as bases tanto para o desenvolvimento desse segundo caminho quanto para a elaboração de questões mais específicas a ele inerentes, como, por exemplo, aquelas da arte e da técnica, detalhadas em várias ocasiões a partir dos anos 30 até o final dos anos 60 (Cf. Herrmann, 1994b, p. 85-221).

${ }^{1} \mathrm{O}$ escrito Beiträge zur Philosophie, publicado em 1989 como volume 65 das Obras completas, foi recentemente traduzido ao português. Cf. Heidegger. Contribuições à filosofia, 2015. 
Levando-se em conta o assunto geral do presente artigo, isto é, a reflexão heideggeriana sobre a arte, é imprescindível, portanto, o horizonte especulativo dos Beiträge, que assegura o enquadramento apropriado da problemática (Cf. Id., 1994a, em particular p. 1-38). O projeto dessa obra capital já está fixado em suas linhas essenciais em 1932, embora o texto tenha sido redigido entre 1936 e 1938. Não é por acaso que, precisamente nos anos 1931-1932, Heidegger escreve uma primeira versão do ensaio sobre a origem da obra de arte (Cf. Heidegger, 1989a), cuja elaboração madura e mais conhecida é aquela publicada em Holzwege como reprodução das três conferências ministradas em Frankfurt em 1936. Fica então evidente que a primeira concepção do ensaio Der Ursprung des Kunstwerkes, em que a filosofia da arte heideggeriana toma forma, remonta ao mesmo período de definição do projeto dos Beiträge, mostrando assim sua conexão com essa obra maior.

O curso universitário sobre os hinos de Hölderlin Germânia e O Reno, ministrado em 1934-1935, também pertence, segundo nosso raciocínio, à mesma fase de gênese e elaboração da reflexão heideggeriana sobre a arte na primeira metade dos anos 30. A suposição de que o ensaio sobre a obra de arte e o curso de 1934-1935 fazem parte de um projeto comum de compreensão do fenômeno artístico nos parece confirmada pela presença, em ambos os textos, das mesmas coordenadas teóricas, dentre as quais a mais importante é, sem dúvida, a caracterização da arte como instauração da verdade do ser. Além disso, há uma série de referências explícitas que provam o entrelaçamento íntimo entre os Beiträge, o curso sobre Hölderlin e o ensaio sobre a obra de arte. Nas Contribuições, Heidegger se refere tanto às conferências sobre a obra de arte quanto ao curso universitário 
de 1934-1935 (Cf. Heidegger, 2015, p. 382 e p. 37). No ensaio, aliás, o filósofo menciona genericamente os hinos de Hölderlin e depois, em particular, o poema $O$ Reno (Cf. Id., 2012, p. 1032), ao qual é dedicada a segunda parte do curso de 1934-1935. Tanto a recorrência das mesmas ideias chave quanto a presença dessas referências explícitas revelam uma coordenação entre os objetivos do ensaio e os do curso - coordenação garantida, em última análise, pela comum pertença deles ao horizonte especulativo das Contribuições.

Baseando-se numa leitura combinada dessas três fontes textuais, o presente artigo se propõe um duplo objetivo teórico. Em primeiro lugar, pretende mostrar a centralidade da noção de afeto ou tonalidade emotiva fundamental (Grundstimmung) na filosofia da arte heideggeriana, fazendo assim emergir a especificidade da concepção heideggeriana da afetividade ${ }^{2}$. Nessa perspectiva, defende-se que a compreensão filosófica da obra de arte implica, no que se refere a sua tarefa preliminar, uma análise fenomenológica do afeto fundamental. Isso parece estar em contradição com a crítica de Heidegger à concepção metafísica da arte - por ele chamada "estética" - a qual veria no estado sentimental o ponto de partida e o ponto de chegada da obra (Cf. Id., 1990, p. 7). Contudo, a crítica de Heidegger à centralidade do sentimento na estética tradicional não pretende negar a importância do componente afetivo na experiência e na compreensão da arte, mas apenas excluir uma determinada interpretação redutora do fenômeno emotivo em favor de uma visão alternativa, que é, ao contrário, compatível com a sua filosofia da arte - sendo, de fato, essencial para ela.

\footnotetext{
${ }^{2}$ A novidade da abordagem heideggeriana da afetividade em comparação com a tradição metafísica é bem destacada no estudo de Coriando, 2002.
} 
Como segundo objetivo, o artigo se propõe a esclarecer a conexão entre a questão da arte e a meditação sobre aquela que poderíamos chamar de "transcendência teológica". É verdade que essa expressão é utilizada no curso universitário de 1928 sobre os Princípios metafísicos da lógica para designar um modelo negativo de transcendência do qual Heidegger quer se distanciar (Cf. Id., 1978, p. 206-208). Todavia, sua abordagem crítica da chamada transcendência teológica não nos impede de também atribuir a essa noção um sentido positivo, desde que sejam excluídos dele os aspectos mais problemáticos destacados por Heidegger. Explorando essa direção, propomos a expressão "transcendência teológica" para indicar a relação do ser humano com o "último deus" (letzter Gott), figura que é tematizada na "fuga" - ou parte compositiva - final dos Beiträge. Em particular, pretende-se mostrar como a arte configura um lugar exemplar no qual ocorre a transcendência teológica assim entendida. Essa ideia fundamental é confirmada, de maneira mais ou menos explícita, não somente pelo texto dos Beiträge, mas também pelos outros escritos heideggerianos sobre a arte, nos quais ela é claramente pensada como lugar de epifania do sagrado ${ }^{3}$.

Enfim, já podemos antecipar que os dois objetivos teóricos almejados trazem à luz aspectos interdependentes do fenômeno

\footnotetext{
${ }^{3}$ Que a obra seja caminho para a manifestação do sagrado depende do seu estatuto de coisa (Ding), ou seja do fato de que ela é reunião da Quadrindade (Geviert) e, portanto, ponto de encontro entre divinos e mortais. Acerca disso: Heidegger. A coisa, 2006, p. 160: "Coisificando cada vez de modo diferente, são coisas espelho e broche, livro e quadro, coroa e cruz" (grifo nosso). Um exemplo emblemático de como a arte abriga a revelação instantânea do sagrado é oferecido pelo breve mas denso texto heideggeriano sobre o quadro de Rafael Madonna Sixtina. A tradução, assim como um excelente comentário desse texto, encontram-se em Borges-Duarte, 2014, p. 54-86.
} 
artístico, duas realidades estreitamente entrelaçadas. De fato, a tonalidade emotiva fundamental que entra em jogo na obra de arte desempenha um papel decisivo para o abrir-se do homem à dimensão do divino. A Grundstimmung resulta ser o medium da interrelação homem-ser, por um lado, e, por outro, daquela homem-deus: assim, ela torna possível que a arte realize a fundação do ser, e nos conceda uma possibilidade privilegiada de encontro com o divino.

\section{A hermenêutica da obra como fenomenologia do afeto fundamental}

No contexto dos Beiträge, a arte é considerada abrigo (Bergung) da verdade do ser no ente criado como obra ${ }^{4}$. A noção de Bergung é apresentada nos $\S \S 243-247$ (Cf. Heidegger, 2015, p. 379-382) e indica a vocação essencial do homem em seu serviço ao ser, sendo esse último concebido como a dinâmica originária de desvelamento e retraimento por meio da qual a manifestação dos fenômenos, o mostrar-se dos entes, torna-se possível. Em particular, o abrigo deixa-se explicar a partir do conceito básico de acontecimento apropriador (Ereignis), termo que indica o mútuo relacionamento entre homem e ser, especialmente evidente no fato de que o Dasein, em seu existir e projetar, sempre pressupõe o acolhimento do lance (Zuwurf) do ser, ou seja do seu dar-se histórico-epocal. "Abrigar" a verdade significa fazer do ente a esfera na qual toma forma visível, ou, lato sensu, experimentável, a dinâmica inaparente do ser. Na época atual, que é o ponto culminante da história da metafísica, o ente reduzido

\footnotetext{
${ }^{4} \mathrm{~A}$ arte é uma das vias de abrigo ao lado de outros modos, como, por exemplo, o pensamento filosófico, o ato formador de Estado e a fabricação de utensílios. Cf. Heidegger, 2015, p. 252 e p. 73.
} 
a objeto manipulável do comportamento técnico não deixa mais transparecer o dar-se do ser, o qual, por seu turno, retrai-se e reforça a sua inclinação ao escondimento. Contra essa tendência decadente, o abrigo busca aproximar novamente ser e ente por meio da mediação humana. Dessa maneira, o ente pode voltar a manifestar-se dentro do cone de luz do ser, recuperando a sua plena essência - nublada, ao contrário, na época da técnica moderna e do domínio da razão calculadora.

A noção de abrigo pode ser considerada como uma reformulação do conceito de "ser-junto-a" (Sein-bei) definido na analítica existencial. Isso não deve surpreender; o próprio Heidegger dá a entender que as aquisições teóricas da Ontologia Fundamental, e portanto também os existenciais nela elaborados, continuam válidos na segunda fase de seu pensamento - desde que submetidos a uma revisão, a uma reformulação ${ }^{5}$. Em Ser e tempo, o serjunto-a é um dos três momentos da cura, ao lado da facticidade e da existencialidade ${ }^{6}$, os quais são caracteres indicadores respectivamente dos existenciais da afetividade $(\text { Befindlichkeit })^{7} \mathrm{e}$ do compreender (Verstehen). Com a noção de Sein-bei, indica-

\footnotetext{
${ }^{5} \mathrm{Na}$ observação preliminar à sétima edição de Ser e tempo do ano de 1953 (Heidegger, 2006, p. 33), o filósofo afirma que "após um quarto de século [...] o seu caminho [isto é, a primeira parte publicada de Ser e tempo] permanece ainda hoje um caminho necessário", contanto que ele seja exposto "de maneira nova".

6"A totalidade existencial de toda a estrutura ontológica da presença deve ser, pois, apreendida formalmente na seguinte estrutura: o ser da presença diz anteceder-a-si-mesma-no-já-ser-em-(no mundo)-como-ser-juntoa (os entes que vêm ao encontro dentro do mundo). Esse ser preenche o significado do termo cura" (Ibid., § 41, p. 259-260).

${ }^{7}$ Propomos de traduzir Befindlichkeit com "afetividade", seguindo a proposta da estudiosa italiana Annalisa Caputo que traduz Befindlichkeit com "affettività". Ver Caputo, 2001.
} 
se a capacidade do Dasein de interpretar o ente ${ }^{8}$ a partir de uma prévia compreensão do ser. Interpretar quer dizer desvelar, trazer à luz o significado de certo ente, ou seja sua utilidade ou importância para o projetar humano. Do mesmo modo, o abrigo consiste num trazer à manifestação, num deixar brilhar a essência do ente na sua pertença ao ser. Também o abrigo é, portanto, um interpretar, só que aqui o desvelamento do ente não acontece em vista do projeto humano, mas da possibilidade de uma manifestação aberta do ser.

A analogia formal entre o ser-junto-a e o abrigo concerne também um outro aspecto. De acordo com os pressupostos da Ontologia Fundamental, o ser-junto-a se revela uma capacidade fundamentada não somente no compreender ${ }^{9}$, mas sobretudo na afetividade. Esta última indica uma maneira originária de acesso ao âmbito fenomenal, o modo passivo-afetivo pelo qual o Dasein se abre à dimensão do ser e interage com os entes. O homem não está em contato com os entes somente porque projeta ativamente um qualquer comportamento com eles, mas, desde sempre, encontra-se passivamente exposto aos entes e à sua presença, de modo a ser tocado e afetado por eles. Isso acontece porque o homem é previamente determinado em seu modo de ser pela afetividade ${ }^{10}$. Da leitura de Ser e tempo pode-se inferir que

\footnotetext{
${ }^{8} \mathrm{O}$ "ser-junto-a" designa o conjunto dos dois momentos da circunvisão (Umsicht) e da consideração (Rücksicht), ou seja: aquelas modalidades interpretativas que guiam respectivamente a ocupação (Besorgen) e a preocupação (Fürsorge). A interpretação é objeto do $\S 32$ (Heidegger, 2006, p. 209-215).

9"A interpretação funda-se existencialmente no compreender e não viceversa" (Ibid., § 32, p. 209).

${ }^{10} \mathrm{~A}$ afetividade é aquela determinação constitutiva da existência, em virtude da qual o Dasein pode ser tocado pelo que vem ao encontro dentro do mundo (Ibid., § 29, p. 196). Ao mesmo tempo a afetividade é, ao lado
} 
essa última capacidade é preliminar, ou anterior, com respeito ao interpretar - não no sentido de que a interpretação aconteça num segundo instante cronológico, após o contato afetivo, como se antes se sentisse algo e somente depois se o interpretasse. Trata-se, ao contrário, de uma primazia ontológica ${ }^{11}$, na medida em que a afetividade é a condição de possibilidade do interpretar, aquilo que o torna possível. O homem não poderia projetar sobre os entes um significado se antes não tivesse experimentado a realidade deles, seu simples subsistir, por meio do canal de contato da afetividade.

Se voltarmos agora à noção de abrigo, tal como abordada nos Beiträge, poderemos fazer uma observação análoga, ou seja: destacar que ela está fundamentada na afetividade. Essa correspondência poderia parecer problemática, visto que o termo Befindlichkeit está ausente nas Contribuições. Contudo, a constatação dessa ausência terminológica não nos parece uma prova suficiente para atestar a ausência conceitual de tal noção. Para a Befindlichkeit, vale o mesmo discurso que conduzimos acerca do ser-junto-a e que poderíamos aplicar a cada existencial da Ontologia Fundamental. Não nos parece provável que, nos anos 30, Heidegger pretendesse abandonar as aquisições anteriores, nem mesmo o existencial da Befindlichkeit. Embora nas Contribuições o filósofo não faça uso desse termo, ele assume implicitamente uma certa compreensão da Befindlichkeit, a qual é parcialmente revisada com respeito à sua formulação anterior.

do compreender, um dos "dois modos" de abertura do Dasein ao seu Da, ao âmbito do ser (cf. Ibid., § 28, p. 192).

${ }^{11}$ A tese dessa primazia ontológica da afetividade, válida tanto na Ontologia Fundamental quanto no pensamento da história do ser, é amplamente argumentada em Pasqualin. Il fondamento "patico" dell'ermeneutico, 2015, e, mais sucintamente, em Pasqualin, 2015. 
Provavelmente com vistas a evitar que essa noção pudesse ser tomada apressadamente como o exato equivalente do que foi pensado em Ser e tempo, Heidegger deve ter preferido não utilizar tal termo. Contudo, o conceito de Befindlichkeit, ou seja a ideia de que o Dasein se abre preliminarmente ao ser e aos entes por meio da sua afetividade, está operando nas Contribuições. O que muda entre Ser e tempo e os Beiträge é a descoberta de que o Dasein é sempre determinado pelo ser num sentido afetivo. Em outras palavras, o ser exerce sobre o homem uma influência emotiva, ou, como se afirma nos Beiträge, o ser é die stimmendbestimmende Macht: aquela potência que o determina e o afina afetivamente (Cf. Heidegger, 2015, p. 442). O ser não é, portanto, um acontecimento indiferente para o ser-aí, mas sempre o toca e o envolve na sua afetividade. O acontecimento do ser tem um impacto sobre o homem; é por ele experimentável, primeiramente por meio da afetividade.

Essa ressonância emotiva do ser no homem é particularmente evidente na leitura, feita nos Beiträge, do fenômeno da Stimmung, do afeto ou tonalidade. No que diz respeito a esse conceito, permanece válido o que Heidegger começara a mostrar pelo menos a partir do curso universitário de 1924 sobre a Retórica de Aristóteles ${ }^{12}$. A tonalidade, ou o humor, é um fenômeno que concerne o homem enquanto ser-no-mundo, enquanto existência que sempre se relaciona consigo e com os entes intramundanos e que não é separável do contexto histórico-experiencial em que está situada. Portanto, a tonalidade não descreve o estado psíquico pontual de um sujeito dualisticamente oposto ao

${ }^{12} \mathrm{~A}$ sua compreensão da tonalidade afetiva começa a se formar graças à assimilação da doutrina aristotélica do pathos, que teve lugar no curso universitário do ano de 1924. Ver Heidegger, 2002. 
mundo, mas o modo em que a existência está relacionada a si mesma e aos entes do seu horizonte mundano. Em outra passagem dos Beiträge, Heidegger compara a tonalidade com uma espécie de atmosfera em que estamos imersos e que permeia tanto a existência quanto os entes com os quais ela lida ${ }^{13}$. Além disso, em Ser e tempo, Heidegger estabelece uma demarcação entre o conceito de Befindlichkeit e aquele de Stimmung, distinguindo o plano ontológico do plano ôntico. A afetividade se apresenta como o pressuposto ontológico da tonalidade ${ }^{14}$, concebida como aquele humor em que a existência está concretamente, ou seja: onticamente, situada. Se o homem não fosse um ente capaz de interagir afetivamente com a sua realidade, não poderia ser tomado pelos vários humores particulares, como, por exemplo, o medo, o prazer, etc.

Se, por um lado, essa caracterização do humor permanece válida nas Contribuições, por outro, Heidegger aprofunda ainda mais esse conceito - descobrindo a sua conexão fundamental com o acontecimento do ser. Do texto das Contribuições, pode-

13،Tudo se dá como se uma tonalidade afetiva sempre estivesse aí, como uma atmosfera, na qual sempre e a cada vez imergimos, e desde a qual, então, seríamos transpassados por uma afinação. [...] Tornou-se evidente que as tonalidades afetivas não são algo que está apenas presente como um dado, mas que elas mesmas são [...] um modo e um jeito fundamental do ser-aí, [...] mas um jeito no sentido de uma melodia, que não paira sobre a assim chamada presença subsistente própria do homem, mas que fornece para este ser o tom, ou seja, que afina e determina o modo e o como de seu ser" (Heidegger, 2006, p. 80-81).

14"O que indicamos ontologicamente com o termo disposição (Befindlichkeit) é, onticamente, o mais conhecido e o mais cotidiano, a saber, o humor (Stimmung), o estar afinado num humor". Quanto à relação entre Befindlichkeit e Stimmung vale, do ponto de vista formal, a mesma distinção que Heidegger faz entre fala (Rede) e linguagem (Sprache), sendo a primeira "o fundamento ontológico-existencial" da segunda (Id., 2006, p. 223). 
se inferir claramente que a tonalidade é sempre o fruto do acontecimento do ser, representando a reação do homem ao seu dar-se originário. A tonalidade não indica, portanto, somente o modo de nosso relacionamento com nós mesmos e com os demais entes, humanos e não humanos, mas sobretudo a maneira como o homem se deixa tocar e transformar pelo ser (também no sentido privativo da indiferença). No $\S 6$ Heidegger nos diz que "a tonalidade afetiva é a pulverização do estremecimento do ser como acontecimento apropriador no ser-aî" (Op. Cit., p. 25), isto é, que a tonalidade é a ressonância emotiva que a dinâmica do ser, oscilante entre retraimento e doação (por isso ele estremece), imprime no homem.

Nos Beiträge, Heidegger atribui um papel central ao fenômeno do afeto fundamental (Grundstimmung), que representa um tipo especial de tonalidade emotiva. Já no curso universitário de 1929-1930 o filósofo reflete sobre essa diferença acentuando, no afeto fundamental, o aspecto epocal ${ }^{15}$, ou seja o fato de que ele exprime o tom emotivo dominante de uma dada fase da história e de uma certa comunidade. Esse traço distintivo se mantém também nos Beiträge, nos quais Heidegger fala de várias tonalidades emotivas fundamentais, associando-as a determinadas épocas da história do ser. Um aspecto ulterior da Grundstimmung é a constância da sua ação, que a torna uma tendência emotiva subjacente do nosso ser e influente sobre as variações emotivas mais fugazes ligadas a circunstâncias particulares $^{16}$. Seja como for, é indiscutível, tanto na primeira

\footnotetext{
${ }^{15}$ Em Heidegger, 2006, p. 212, o filósofo mostra que o acontecimento da tonalidade afetiva fundamental está enraizado na história do ser-aí. Por essa razão a tonalidade fundamental "se transforma e não se impõe obrigatoriamente para toda e qualquer época".

16،Esta [a disposição fundamental] dispõe, sempre e desde o fundo, todas
} 
quanto na segunda fase da reflexão heideggeriana, o fato de que a Grundstimmung, ou a Grundbefindlichkeit (como ainda é designada em Ser e tempo), é caracterizada pela radicalidade e a profundidade da revelação que ela oferece. Esse é um ponto decisivo, que assinala uma distância ulterior de Heidegger com respeito à visão tradicional do afetivo, que tendia a considerar os sentimentos como cegos, desprovidos de conteúdo heurístico, ou, em todo caso, confusos, capazes de nos manifestar algo, mas só limitada e menos claramente do que o intelecto.

A centralidade da tonalidade afetiva fundamental nas Contribuições se deduz inequivocamente da afirmação heideggeriana de que a retenção (Verhaltenheit) é o fundamento da cura ( $O p$. Cit., p. 38). A retenção é, segundo Heidegger, uma Grundstimmung exemplar, predominante na época de transição e preparação para "o outro início" (der andere Anfang), isto é, para o pensamento pós-metafísico. Ela indica uma disposição receptiva e não-impositiva pela qual o homem capta e acolhe o acontecimento do ser que ressoa apenas debilmente em nossa época. O que nos interessa agora é sublinhar que, precisamente, um afeto fundamental é aqui elevado a fundamento da cura, a qual indica, por sua vez, aquela estrutura tripartida da qual o ser-junto-a constitui um momento essencial. Levando-se em conta que o abrigo é a reformulação conceitual do ser-junto-a, pode-se afirmar, de maneira coerente, que a Grundstimmung é o fundamento do abrigo enquanto momento da cura. Mas isso significa que também a arte, sendo uma modalidade do abrigo, está enraizada na tonalidade afetiva fundamental. Essa implicação, deduzível mais linearmente do texto dos Beiträge, permite,

as disposições essenciais e, além disso, determina para cada uma delas o seu lugar hierárquico" (Id., 2004, p. 141). 
aliás, trazer à luz um ponto mais implícito: uma vez que a Befindlichkeit constitui o pressuposto ontológico da Grundstimmung, a arte resulta ser, afinal, fundada na própria afetividade. A esse respeito, precisemos que a terminologia do "fundamento" e do "fundar", irrenunciável em Heidegger, apesar da sua aversão aos fundamentos metafísicos, refere-se à relação na qual um elemento possibilita outro e o conserva no seu traço essencial ${ }^{17}$.

Confirma-se assim a analogia entre o fundar-se do ser-junto-a na afetividade e o enraizamento do abrigo na tonalidade emotiva fundamental. Para nossa compreensão da arte isso é um ponto decisivo. É usual ler a filosofia da arte heideggeriana a partir do enfoque no lado projetual que caracteriza a grande arte, ou seja, no fato de que ela sempre levanta um mundo, funda uma época histórica, instaura a verdade do ser e aquela do ente. Todos esses são aspectos decisivos da concepção heideggeriana do fenômeno artístico, mas nós gostaríamos de atentar para o caráter, menos explorado, da Geworfenheit, ou do estar-lançado, da arte.

Em geral, o conceito de estar-lançado, já presente em Ser e tempo, mas talvez em parte ofuscado pelo momento do projeto ${ }^{18}$, ganha maior visibilidade nas Contribuições - sendo repensado

${ }^{17}$ Para o sentido preciso da "relação de fundamento": "Não há vazio sem livre. O vazio é fundamentado no livre. Que relação de fundamento é essa? [...] Um fundamento (Grund) factual diz que uma coisa não pode ser sem outra. Vazio não pode ser sem 'livre'; 'livre', isto é, ocupável é mais original do que 'vazio"' (Heidegger, 2001, p. 43).

${ }^{18}$ Sobre a relação entre projeto e estar-lançado, veja-se: Heidegger. Ser e tempo, 2006, § 31, p. 202-209. Na articulação de Ser e tempo, sobressai a ideia da antecipação da morte, a qual se apresenta como uma conversão do estar-lançado por excelência, da mortalidade, num dado projetável enquanto antecipável. Dessa maneira, o estar-lançado permanece ofuscado pela centralidade do projeto, ao qual o primeiro momento é rapidamente assimilado. 
a partir do conceito de Zuwurf, de lance do ser. Heidegger descreve a estrutura do acontecimento apropriador por meio do conceito de viragem (Kehre) (Id., 2015, p. 257), com o qual indica-se a mútua referência entre o momento do jeito do ser, da sua doação, e aquele do projeto, ou seja da resposta hermenêutica do homem que assume aquela dádiva e lhe dá forma e palavra.

O estar-lançado da obra de arte não se refere ao simples fato de que a obra pertence ao horizonte mundano e, portanto, atravessa, juntamente com ele, um processo de decadência, ulteriormente agravado pela configuração técnica de nosso mundo contemporâneo, que condena a arte às leis do consumo de massa. A Geworfenheit da obra tem a ver, num sentido essencial, com o lance do ser, sendo a obra concebida como uma forma de realização do projeto hermenêutico "lançado" pelo ser.

Consequentemente, examinando de perto o lance do ser, poderse-á entender melhor também o estar-lançado da obra. Qual é o estatuto do lance do ser? Parece-nos justificado excluir que o acontecimento do ser consiste em algo linguístico, que a sua doação indica a transmissão de uma mensagem verbal e discursiva. A confirmação dessa suposição pode ser encontrada sobretudo em duas fontes textuais: 1. o curso sobre Heráclito do ano de 1944 (Logik. Heraklits Lehre vom Logos); 2. o volume 74 das Obras completas intitulado Zum Wesen der Sprache und zur Frage nach der Kunst ${ }^{19}$. Não podemos conduzir, aqui, uma exploração detalhada dessas fontes, a qual foi exposta num outro lugar, mas gostaríamos, pelo menos, de mencionar os princi-

\footnotetext{
${ }^{19} \mathrm{O}$ volume reúne vários textos - notas, anotações e breves ensaios - os quais têm em comum a referência aos temas da linguagem e da arte. Os textos reunidos no volume são, em sua maioria, inéditos e datam do período que vai do final dos anos 30 até o começo dos anos 60 .
} 
pais resultados dessa análise. Da primeira fonte citada se pode extrair a ideia de que o ser, concebido como Logos, não indica algo de estritamente linguístico, mas o acontecimento do recolhimento (Ver-sammlung) originário pelo qual o ser faz advir os entes na sua manifestação e os reconduz à sua essência ${ }^{20}$. Do curso de 1944 não resulta somente que o ser é um acontecimento $a$ linguístico, mas também que ele, enquanto origem e premissa da linguagem humana ${ }^{21}$, é pré-linguístico. Quanto à segunda fonte mencionada, deve sublinhar-se que Heidegger qualifica o darse do ser, também chamado de "palavra primeira" (Heidegger, 2010, p. 132), como "voz afinadora" (stimmende Stimme) (Ibid., p. 153), querendo assim aludir a um acontecimento melódicoafetivo - aquele pelo qual o ser afina afetivamente o homem. Embora nas duas fontes Heidegger se refira ao ser em termos de Logos e palavra, isso não implica, contudo, que ele conceba o acontecimento do ser como um fenômeno linguístico. Pode-se até mesmo destacar que, no volume 74, Heidegger fala explicitamente de uma Stimmung do ser (Cf. Ibid., p. 18), tendo em mente, provavelmente, o fenômeno do favor ou da kháris, a que ele se dedica numa outra parte do mesmo volume (Ibid., p. 44-47). Referências à kháris recorrem também na conversa entre o "japonês" e o "pensador" (Cf. Ibid., p. 111-112) e em "...Poeticamente o homem habita..." (Op. Cit., p. 180): a kháris indica o conceder-se benevolente do ser, em virtude do qual o homem é capaz de pensamento, palavra e poesia. Esses textos

20"Por enquanto ganhamos só uma coisa: o significado corrente de leghein e logos - no sentido de assertar, dizer, discurso, palavra e significado de palavra - não traz à luz a essência originária do Logos" (Heidegger, 1987, p. 270). Ver também: Ibid., p. 376-380.

21"O Logos não é a palavra. Ele é mais originário que ela, sendo a premissa (Vorwort) de qualquer linguagem" (Heidegger, 1987, p. 383). 
confirmam que o lance, ou a doação do ser, consiste no acontecimento do propagar-se da kháris enquanto tonalidade emotiva do ser. Como emerge desse rápido esboço, o dar-se do ser não é de natureza linguística, mas de natureza afetiva, ou "páthica", denotando o acontecimento de um pathos originário benevolente que toca o homem e ativa a sua capacidade linguístico-pensante.

Se assim se caracteriza o lance do ser, deve-se agora esclarecer de qual maneira o homem acolhe esse acontecimento para poder projetá-lo em palavras e obras. Sendo de natureza afetiva e pré-linguística, esse lance do ser não pode ser recebido pelo Dasein por meio de uma escuta linguística. Deve, ao contrário, entrar em jogo a Befindlichkeit como aquele canal que permite experimentar o transmitir-se afetivo do ser. O acolhimento humano não consiste em ouvir uma mensagem linguística qualquer, enviada pelo ser, mas em sentir sua Stimmung por meio da $B e$ findlichkeit. Portanto, a afetividade aparece como o medium da relação entre ser e homem.

Voltamos, então, à questão da qual partimos: a do estarlançado da arte. Na arte, o homem projeta a verdade do ser, correspondendo ao lance. Verificou-se, no entanto, que esse lance é de natureza "páthica" e é acolhido pelo homem por meio da $B e$ findlichkeit. Torna-se claro, portanto, que a arte é fundada na afetividade enquanto medium em que o homem acolhe o lance "páthico" do ser. É precisamente nesse enraizamento afetivo do projeto artístico que consiste, afinal, seu caráter de Geworfenheit. Essa conclusão nos permite esclarecer, ao mesmo tempo, em que sentido a arte se funda na Grundstimmung. Essa última é uma maneira exemplar de Stimmung, uma experiência de particular intensidade afetiva e reveladora. Na tonalidade afetiva fundamental, o homem é completamente envolvido pelo 
dar-se do ser, do qual descobre a dinâmica afetiva profunda e reconhece, nela, a essência originária da verdade. Transformado e inspirado por essa experiência de envolvimento e revelação, o homem é impulsionado para dar-lhe voz e figura experimentável, para projetá-la artisticamente.

Contudo, se nos limitarmos à consideração do ensaio heideggeriano sobre a obra de arte, o aspecto do estar-lançado, isto é, o fundamento dela na Befindlichkeit e na Grundstimmung, não vem à luz. De fato, no ensaio heideggeriano, o termo Stimmung se apresenta só uma vez, e, pelo menos aparentemente, como referência rápida e marginal (Id., 2012, p. 18). São, ao contrário, os Beiträge que, na ideia do abrigo e do que chamamos de lance "páthico", permitem dar à questão da arte o enquadramento adequado, e compreender, num sentido genuíno, o estar-lançado do produzir artístico. Uma tematização e exemplificação da relação arte-Grundstimmung, que é delineada, em termos teóricos, nas Contribuições, é oferecida no já mencionado curso universitário sobre os hinos de Hölderlin. Nesse curso, Heidegger reconhece explicitamente a proveniência do dizer poético (mas, implicitamente, de cada produção artística) da tonalidade emotiva fundamental. Tome-se como exemplo uma passagem emblemática do curso, na qual Heidegger esclarece que o posicionamento e a escolha das palavras de um poema são sempre preliminarmente definidas pela composição rítmica - a qual é, por sua vez, predeterminada por certa Grundstimmung (Cf. Id., 2004, p. 24). Em outra passagem do texto do curso, o filósofo afirma que "a voz do dizer tem de estar afinada" e "que o poeta fala partindo de uma disposição interior" (Ibid., p. 81). E, de fato, a interpretação heideggeriana sobre os hinos de Hölderlin se baseia numa exploração da tonalidade emotiva fundamental do "luto sagrado", 
que o filósofo individualiza como aquela disposição peculiar que marca o dizer do poeta, tanto em seus conteúdos quanto na forma ${ }^{22}$.

Sendo enraizada na tonalidade emotiva fundamental, a obra de arte tem, aliás, o poder de despertar no público, nos indivíduos, ou em certa comunidade histórica, o mesmo estado afetivo. São numerosas as passagens do curso de 1934-1935 em que Heidegger mostra que na poesia, e, portanto, implicitamente em cada obra de arte, acontece a instituição de uma tonalidade afetiva fundamental. "Instituir" não significa aqui engendrar no público um humor qualquer antes inexistente, mas "despertar" uma tonalidade (Ibid., p. 139-140), a qual, portanto, já deve habitar de maneira latente no homem, embora não seja escutada, por causa de uma prevalente atitude inautêntica e da necessidade de tranquilização. De maneira análoga à filosofia, tal como é vista no curso universitário de 1929-1930²3, parecenos que também a poesia e a arte apelam a estados de alma habitualmente removidos dos sujeitos, mas que podem ser frutuosamente despertados a fim de estimular um comportamento questionador e de transformar a maneira de pensar dos homens. A arte tem, nesse sentido, o poder "retórico" de despertar as "grandes paixões" e isso em virtude do fato de que já o artista experimenta, na sua própria pele, a tonalidade emotiva fundamental - criando a obra a partir dela ${ }^{24}$.

${ }^{22}$ Uma análise da interpretação heideggeriana do hino de Hölderlin Germânia, com particular enfoque na caracterização da disposição fundamental, é conduzida em: Werle, 2004, p. 145-154.

${ }^{23}$ Os conceitos Fundamentais da Metafisica. Se à primeira parte desse curso universitário é atribuída a tarefa de despertar nos ouvintes uma tonalidade emotiva fundamental, na segunda parte trata-se de levantar, a partir dessa experiência afetiva, as três perguntas básicas do filosofar.

${ }^{24}$ Sabe-se que a hermenêutica da facticidade e a analítica existencial 
À luz da conexão arte-Grundstimmung, iluminada pelos Beiträge e pelo curso sobre Hölderlin, é possível ler o ensaio sobre a obra de arte sob uma nova perspectiva. Se é verdade que esse ensaio não contém nenhuma menção explícita da relação arte-Grundstimmung, o leitor que abordar o texto tendo consciência daquela conexão poderá entrever, em pelo menos duas passagens, a referência tácita ao afeto fundamental. Em primeiro lugar, captura nossa atenção o conceito de choque, que Heidegger considera uma marca da grande arte (Id., 2012, p. 68-70). O choque exprime um aspecto duplo: por um lado, a experiência do fato surpreendente de que a obra é, sendo uma realidade que antes não existia e que agora é criada do nada; por outro, o movimento subitâneo de ruptura, pelo qual a obra nos arrebata de uma imersão cega no ente para nos transferir para a abertura da verdade do ser, negligenciada na prática diária. Já o primeiro aspecto do choque nos sugere que estamos às voltas, aqui, com o fenômeno da Grundstimmung: no movimento no qual o habitual (o simples fato de que o ente é) torna-se

pressupõem a leitura e a assimilação da Ética a Nicômaco de Aristóteles (é emblemático, nessa direção, o estudo de Volpi, 1996). Parece-nos interessante destacar como, ao contrário, na ideia heideggeriana da arte enquanto instituição do afeto fundamental, ressoam alguns motivos da Retórica e da Poética. No que diz respeito à Retórica, objeto do curso já citado de 1924, pode-se estabelecer uma analogia entre a figura aristotélica do orador e aquela heideggeriana do poeta, ambos os quais têm o poder de agir sobre as emoções do público e de canalizá-las em determinadas direções. Quanto à Poética, limitamo-nos a ressaltar a ideia aristotélica segundo a qual o roteiro bem construído, em equilíbrio entre verossímil e imprevisto, é tal que desperta o thauma, o assombro. Veja-se em particular: Aristóteles, Poética, XXIV, 1460 a, 12: "o maravilhoso tem lugar primacial na tragédia" (Trad. port. Eudoro de Sousa, 1966, p. 98). Acerca desse ponto, entrevê-se uma analogia com a ideia heideggeriana do choque produzido na grande arte - choque que apresenta as características do assombro. 
extraordinário (tratando-se de um ente que antes não existia), pode-se reconhecer a dinâmica própria do assombro (Erstaunen), assombro do qual Heidegger trata no curso universitário de 1937-1938 (Cf. Id., 1984, p. 151-181). Mas é sobretudo o segundo aspecto - aquele da "remoção" (Verrückung) do âmbito ôntico e da inserção no acontecimento da verdade (Cf. Id., 2012, p. 70) - que consente uma referência mais direta à Grundstimmung. De fato, no curso sobre Hölderlin, Heidegger descreve a tonalidade emotiva fundamental como uma "colocação" (Versetzung $)^{25}$, buscando indicar o movimento de exposição à verdade inerente a cada afeto fundamental. Esse último transfere o $D a$ sein ao acontecimento ontológico da verdade do ser. A analogia entre a remoção produzida pelo choque e a colocação que ocorre no afeto fundamental permite compreender o choque a partir do fato de que a obra sempre desperta uma Grundstimmung no espectador, e assim o transfere do plano ôntico para o plano ontológico, habitualmente esquecido. A obra produz choque porque institui o afeto fundamental, e assim envolve o espectador no jogo ontológico da verdade.

Se nos concentrarmos, agora, na mudança do ôntico para o ontológico que ocorre na obra, perceberemos que se trata de um movimento de transcendência. De fato, na Ontologia Fundamental a transcendência é concebida precisamente como a ultrapassagem, executada pelo Dasein, do plano ôntico para a dimensão ontológica do ser ${ }^{26}$. Nos Beiträge, todavia, Heidegger

25"A disposição fundamental é [.. ] a colocação primordial na vastidão do ente e na profundidade do Ser" (Heidegger, 2004, p. 135).

${ }^{26}$ Nesse contexto, Heidegger apresenta a transcendência como a ultrapassagem, constantemente operada pelo Dasein, em direção ao próprio ser (às possibilidades projetadas), ao ser do mundo (como horizonte significativo e campo de realização das possibilidades) e ao modo de ser dos entes encon- 
exprime uma atitude crítica com respeito à sua anterior concepção de transcendência, porque reconhece nela uma acentuação excessiva, e facilmente sujeita a mal-entendidos, do papel ativo desempenhado pelo sujeito humano (Id., 2015, p. 213-215; p. 247 e p. 314-315). Observando a atitude severa de autocrítica presente nos Beiträge, pareceria necessário concluir que, na segunda fase de seu pensamento, Heidegger teria decidido abandonar o conceito de transcendência. Surge, contudo, a pergunta: seria o conceito de transcendência enquanto tal aquele que Heidegger acaba considerando inutilizável, ou seria, talvez, apenas um de seus aspectos que o filósofo rejeita? Na verdade, acreditamos que é possível formular um conceito de transcendência evitando o aspecto problemático do subjetivismo excessivo. Dessa maneira, obter-se-ia um conceito de transcendência imune à crítica de Heidegger e admissível no quadro do pensamento inaugurado pelos Beiträge. É precisamente a nova abordagem radical da Geworfenheit a partir do lance do ser que nos permite rever a noção de transcendência e dar-lhe uma formulação mais adequada. Nesse quadro teórico, o transcender do Dasein não é mais pensável como um ato executado pelo sujeito por meio da sua compreensão, mas como aquele acesso à verdade do ser que tem lugar no acontecimento concomitante do lance e do projeto humano. O Dasein tem acesso à verdade, ao plano ontológico, apenas na medida em que se expõe passivamente à auto-manifestação do ser. O transcender não pode ser, portanto, compreendido como um fazer ativo do sujeito, mas indica, antes de tudo, o acolhimento humano da doação do ser no medium da Befindlichkeit. O conceito de lance do ser permite,

trados. Essa abertura à dimensão ontológica, lato sensu, é a condição de possibilidade dos comportamentos concretos com os entes. Cf. Id., 1988. 
assim, corrigir o traço ativo-subjetivista que ainda pairava sobre a concepção fundamental-ontológica da transcendência.

O espectador, que, graças à obra, afina-se segundo a tonalidade afetiva fundamental, experiencia o ser na forma de um acolhimento afetivo do seu dar-se. Em virtude da Grundstimmung, ele é transferido para a dimensão da verdade do ser, tornase receptivo a ela por meio da Befindlichkeit e, dessa maneira, transcende. Não é por sua própria iniciativa que ele transcende, mas porque a tonalidade emotiva fundamental despertada pela obra o leva a experimentar a verdade, a perceber afetivamente a doação do ser. Graças à obra, o homem é inserido num movimento de transcendência do qual está consciente. Nessa perspectiva, pode-se dizer que a obra de arte é um lugar privilegiado da transcendência ontológica do Dasein, onde o adjetivo "ontológico" sublinha o fato de que aqui se trata da abertura do homem ao ser.

Um segundo aspecto que revela que a tonalidade afetiva fundamental constitui uma referência implícita ao raciocínio conduzido no ensaio é a afirmação, contida no Epílogo, segundo a qual a vivência (Erlebnis) é o elemento em que a arte morre (Cf. Id., 2012, p. 86). Para entender essa afirmação, atentemos para a noção de Erlebnis, tal como abordada nas Contribuições (Op. Cit., p. 124-133), e que confirma, mais uma vez, que estas compõem o fundo conceitual do ensaio. A vivência representa o fenômeno degenerativo mais emblemático da maquinação ( $M a$ chenschaft), entendida como tendência impositivo-calculadora que impera no modo moderno de lidar com os entes. A vivência indica, num sentido muito amplo, a atitude característica do sujeito metafísico que se relaciona ao ente tendo sempre si mesmo como medida e centro de referência - e que o subordina às suas 
próprias exigências de satisfação e consumo. Em outros termos, a vivência indica a estrutura característica de cada comportamento do homem moderno em relação ao ente, ou seja o fato de ser autocentrado e finalizado ao bem-estar subjetivo. Enquanto estrutura geral de cada modalidade de relacionamento com a realidade, o Erlebnis é uma determinação negativa que pode qualificar também o modo de sentir do homem. Nessa acepção mais restrita, o termo Erlebnis se presta a indicar tanto a concepção metafísico-tradicional do emotivo, quanto a modalidade hoje difundida de um sentir superficial, dirigido à diversão e à mera satisfação. Em ambas acepções, o Erlebnis se apresenta como o conceito oposto à Stimmung e, em particular, à Grundstimmung. Quanto à primeira acepção, Erlebnis é a noção com a qual se pode resumir a concepção tradicional do sentimento criticada por Heidegger: a compreensão do estado emotivo como fenômeno puramente subjetivo e psicológico, ou como acidente que afeta o indivíduo com consequências substancialmente negativas. Na segunda acepção, Erlebnis é o termo que descreve o modo de sentir prevalecente na época moderna, caracterizado pela busca constante de novas distrações, livre de pudor e objeto de espetacularização ${ }^{27}$.

O conceito de Erlebnis é referido por Heidegger à concepção tradicional da arte (Cf. Id., 2012, p. 85), àquela que ele chama de "estética" e que, segundo o filósofo, começa a partir de Platão e culmina na indústria cultural de hoje $\mathrm{e}^{28}$. Na compreensão estética, a obra é definida a partir do Erlebnis, isto é, de um con-

\footnotetext{
${ }^{27}$ Ver o quarto ponto mencionado no $\S 58$ sob o título " $O$ desnudamento, a publicização e a vulgarização da tonalidade afetiva" (Heidegger, 2015, p. 121-122).

${ }^{28}$ Uma visão panorâmica sobre a história da estética encontra-se em: Heidegger. Nietzsche, p. 71-84.
} 
ceito redutor do fenômeno afetivo que não leva em conta nem a realidade do homem como ser-no-mundo, nem o fato de que a tonalidade emotiva exprime a impressão particular deixada em nós pelo ser. Além disso, a compreensão estética acaba condicionando a prática artística hodierna e a sua fruição. Nessa prática, visa-se uma modalidade superficial do sentir: o artista produz arte ao exprimir as suas emoções privadas, tendo por finalidade explícita a de despertar no público uma emoção qualquer que possa diverti-lo.

Nas situações em que a compreensão e a experiência concreta da obra são dominadas pela referência ao Erlebnis, a arte é destinada a morrer. Resumindo, a criação artística genuína é ameaçada tanto pela persistência duma compreensão inadequada da arte (a estética), quanto pelo propagar-se de uma vida afetiva superficial - a qual acaba orientando a criação e a fruição das obras. A referência à vivência enquanto elemento destrutivo da arte atesta que o horizonte especulativo do ensaio sobre a Kunstwerk pressupõe implicitamente a ideia de uma estrita correlação entre arte e disposição fundamental. A afirmação heideggeriana de que a vivência é o elemento em que a arte morre nos parece sugerir quase espontaneamente sua continuação: a Stimmung, ou ainda melhor, a Grundstimmung é o elemento em que a arte vive. Do nosso ponto de vista, isso significa que uma nova compreensão da arte a partir da Stimmung, e a redescoberta de uma afetividade profunda, são as premissas necessárias para manter viva a arte, promovendo uma criação artística genuína.

Permanecendo no campo filosófico, delineia-se assim uma modalidade de leitura e interpretação da obra de arte centrada na análise fenomenológica da tonalidade emotiva fundamental. 
Nessa perspectiva, compreender filosoficamente uma obra quer dizer explorar a tonalidade afetiva fundamental, aquela da qual a obra surge e que é despertada nos destinatários, tanto nos indivíduos como numa comunidade histórica determinada. Já no curso sobre os hinos hölderlinianos, Heidegger nos convida a praticar essa nova hermenêutica da arte. O curso inteiro é a demonstração da tese fundamental segundo a qual, como sugerido por Heidegger no texto, perguntar-se sobre o mais íntimo da obra significa indagar a sua Grundstimmung ${ }^{29}$. Torna-se então evidente que uma tarefa preliminar da hermenêutica da arte é a fenomenologia da tonalidade afetiva fundamental ${ }^{30}$. Para conduzir a exploração fenomenológica do afeto fundamental, Heidegger nos oferece pelo menos dois esquemas interpretativos. O primeiro é aquele posto em prática em Ser e tempo para a análise do medo e da angústia. Trata-se de um esquema tripartido que examina para cada humor: 1. o momento do Wovor, isto é, o âmbito em frente do qual o ser-aí se sente num certo humor; 2. o Wie, o modo como o Dasein se sente quando está disposto numa determinada tonalidade; 3. o Worum, que indica o conjunto daqueles comportamentos ou modos de ser existenciais que são diretamente envolvidos ou afetados pelo humor (Cf. Heidegger, 2006, p. 199-202 e p. 250-258).

\footnotetext{
29"'Perguntamos pelo 'âmago' da poesia, pela disposição fundamental, e isso equivale a perguntarmos pelo Ser que nela se abre e é instituído poeticamente" (Id., 2004, p. 155).

${ }^{30}$ É possível ler as características fundamentais da filosofia da arte heideggeriana à luz do fenômeno da Grundstimmung. Acerca disso referimo-nos a: Pasqualin. Il fondamento "patico" dell'ermeneutico, 2015, p. 720-749. Naquele contexto mostramos, em particular, como a exposição do mundo e da terra, a instituição da verdade, e a fundação da história - traços salientes da caracterização heideggeriana da obra - só são plenamente compreensíveis a partir da dinâmica da tonalidade emotiva fundamental ativa na arte.
} 
Um segundo esquema interpretativo é traçado no curso sobre Hölderlin, no qual Heidegger estabelece quatro momentos estruturais da disposição fundamental: 1. ela "desloca [o Dasein] para fora" (entrückt), para a relação com os deuses; 2. "desloca para dentro" (rückt ein), para a terra; 3. "abre" (eröffnet) para a revelação dos entes; 4. funda (gründet), enfim, um lugar e um tempo para o Dasein histórico (Id., 2004, p. 134). Esses momentos delineiam um esquema quadripartido, segundo o qual a Grundstimmung: 1. torna o homem receptivo para a dimensão divina; 2. deixa-o entrar em contato com a realidade da terra, habitualmente reduzida à reserva desfrutável à vontade; 3. revela e projeta a verdade do ente; 4. determina o habitar humano e traz consigo uma estruturação da temporalidade do Dasein. Não podemos detalhar aqui esses dois esquemas interpretativos, mas limitamo-nos a sugerir a sua aplicabilidade à análise fenomenológica da disposição fundamental. É possível explorar a Grundstimmung característica da obra utilizando as categorias frisadas e ganhar, assim, uma compreensão profunda do fenômeno artístico.

\section{Arte e transcendência teológica}

A expressão "transcendência teológica" aparece, numa acepção negativa, no curso universitário de 1928 sobre os Princípios metafísicos da lógica. Ao definir seu próprio conceito de transcendência, Heidegger se distancia de dois modelos interpretativos: o gnosiológico, de tradição neokantiana, no qual a transcendência é concebida como propriedade do objeto externo alcançado pela consciência intencional; e o teológico, que oferece uma leitura inadequada da transcendência divina (Id., 1978, p. 
204-208). A crítica ao modelo teológico ${ }^{31}$ revela a insatisfação de Heidegger sobretudo com respeito a dois pontos: 1 . o fato de que deus é tema de um pensamento teorético - o que tende a reduzir deus a um simples elo lógico de um discurso demonstrativo; 2. a concepção da transcendência de deus como independente em relação ao mundo e alheio ao ser contingente. O aspecto problemático do modelo de transcendência teológica é, portanto, duplo: por um lado, a ideia de deus encontra-se subordinada a uma necessidade, a uma pretensão da razão de dar à realidade uma ordem tranquilizadora e correspondente às próprias expectativas; por outro, deus é concebido como substância autossuficiente e livre da necessidade, a qual o poderia vincular ao mundo. Como se pode observar, Heidegger critica aqui apenas um modo determinado de pensar deus, mas não recusa qualquer abordagem de tal questão ${ }^{32}$, nem exclui a possibilidade de interpretar diferentemente a conexão entre deus e a transcendência. A crítica de Heidegger não parece, então, estar em contradição com nossa escolha de utilizar a expressão "transcendência teológica" num sentido positivo, do qual, contudo, deverão ser excluídos os aspectos problemáticos aqui ressaltados.

Além disso, também a conferência de 1927 sobre Fenomenologia e teologia parece-nos confirmar implicitamente a possibilidade de uma compreensão genuína da transcendência teológica. Heidegger trata aqui da fé como de uma modalidade possível e legítima da existência. A fé é descrita por Heidegger como a relação da existência com o Deus revelado, o qual, no caso da fé cristã, coincide com Cristo. Considerando o fenômeno da

\footnotetext{
${ }^{31}$ Parece-nos que essa concepção da divindade criticada por Heidegger tem o seu arquétipo em Aristóteles e uma ulterior exemplificação em Descartes.

${ }^{32}$ Para uma análise da questão de deus, tal como abordada por Heidegger no seu pensamento como um todo, ver: von Herrmann, 2012.
} 
fé de um ponto de vista formal e anterior à diferenciação dos conteúdos dogmáticos, ela indica a relação da existência com a dimensão divina e, nesse sentido específico, pode ser designada como transcendência teológica, na qual o adjetivo "teológico" se refere ao pensamento e à experiência de deus. Permanece, contudo, o fato de que, na conferência de 1927, Heidegger exclui a tematização da relação de fé entre homem e deus da análise filosófica. A filosofia deve colocar entre parênteses a questão de deus, a qual pode, ao contrário, ser deixada à abordagem da teologia. Essa posição, exprimida na conferência de 1927, está de acordo com a tese mais geral defendida nos anos 20 segundo a qual a filosofia deve ser, em princípio, ateia ${ }^{33}$. O ateísmo da filosofia não representa, todavia, uma tomada de posição de Heidegger acerca da não-existência de deus, vale apenas como um princípio metodológico do pensamento filosófico, na medida em que o Dasein que filosofa não pode apoiar-se em nenhuma fé devendo, contudo, abrir-se a uma interrogação radical.

A questão da relação homem-deus, excluída programaticamente da Ontologia Fundamental, torna-se central nos Beiträge. É nessa obra que pretendemos basear uma interpretação positiva da transcendência teológica. Embora tal expressão não apareça no texto, ela pode ser aplicada para designar a relação entre o homem e o chamado "último deus" - figura com que Heidegger esboça um conceito autêntico de divindade (Cf. Id., 2015, p. 392-403). Ao delinear essa relação homem-deus, Heidegger mostra estar evitando aqueles aspectos problemáticos que ele

${ }^{33}$ Heidegger exprime essa tese pela primeira vez no curso universitário de 1921-1922 (Heidegger. Phänomenologische Interpretationen zu Aristoteles, 1985, p. 197). A mesma posição é repetida no chamado Natorp-Bericht (Heidegger. Phänomenologische Interpretationen zu Aristoteles, 1989, p. 246). 
tinha ressaltado no mencionado curso universitário de 1928. No que diz respeito ao primeiro ponto, a abordagem da questão de deus é conduzida por um pensamento que abandona tanto a lógica do sistema (Ibid., p. 67-68), em que deus aparece como ente supremo e causa primeira, quanto a atitude calculadora, característica do saber na fase culminante da metafísica. Um raciocínio calculador acerca de deus tenderia a evadir o caráter de mistério, a tornar deus um instrumento útil para os fins da vontade de potência, isto é, uma representação idólatra que serviria de justificação e asseguração. O pensamento inicial ou originário, inaugurado por Heidegger com os Beiträge, propõe-se a preparar a disposição adequada para uma experiência autêntica de deus, despertando a escuta e a consciência dos homens para aquilo que é incalculável e imprevisível.

O segundo aspecto que resultou problemático na crítica heideggeriana ao conceito de transcendência teológica era a concepção da divindade segundo as categorias de imutabilidade e impassibilidade, isto é, a ideia de um deus separado do mundo e livre de necessidades. A esse respeito, é interessante notar que, nos Beiträge, Heidegger atribui ao último deus um conteúdo mínimo de sentido, que é identificável precisamente no aspecto da necessidade. Essa última, elevada a traço essencial da divindade, desdobra-se em duas direções: deus precisa do ser e, ao mesmo tempo, do homem. Necessita do ser como do único horizonte em que pode manifestar-se. O ser, escreve Heidegger, "é aquilo de que a deização do deus precisa" (Ibid., p. 236 a - trad. modificada - [Cf. também Ibid., § 126, p. 240]). Em outras palavras, deus pode tornar-se manifesto para os homens só se a dimensão do ser, isto é, de uma realidade excedente ao dado ôntico, já se revelou à consciência dos homens. Nessa reve- 
lação progressiva, deus precisa também do homem. De fato, se deus pode ser experimentado pelo homem, é porque este último já tem consciência de uma dimensão que transcende os entes, na qual somente há espaço para o encontro com deus. Emblemática nesse sentido é uma passagem do $\S 7$ : "o Ereignis [o acontecimento do ser] confia (übereignet) deus ao homem dedicando (zueignet) esse último a deus" (Ibid., p. 30 - tradução modificada). A citação sugere a ideia de que o homem pode se dedicar a deus somente graças à intermediação do ser, à experiência do seu acontecimento originário. Ao mesmo tempo, o homem resulta ser aquilo ao qual deus é confiado, aquilo que cuida de deus (num sentido amplo de Fürsorge). Muda-se assim de uma concepção de deus como ser autossuficiente, que satisfaz a necessidade humana, para uma ideia de deus como aquilo que precisa do cuidado humano. Como é que se realiza, então, esse cuidado? A pergunta nos permite passar à questão que nos interessa, qual seja, da relação entre arte e transcendência teológica.

Como já foi frisado, a arte é um lugar exemplar da efetivação da transcendência ontológica, ou seja, o espaço em que o homem, tanto o artista quanto o espectador, é conscientemente levado para a dimensão ontológica do ser. Mostrou-se, aliás, que esse movimento de transcendência é mediado pela Grundstimmung, que representa a experiência afetiva que origina a criação artística e que é despertada nos espectadores. Graças a essa disposição emotiva, o homem se abre ao acontecimento do ser, isto é, àquela dimensão na qual pode experienciar deus. Em virtude de sua conexão com a tonalidade afetiva fundamental, a arte se oferece, portanto, como lugar privilegiado de abertura ao ser e, consequentemente, como canal de contato com o último 
deus. Na medida em que a arte desperta no homem a consciência de deus, configura-se como uma modalidade concreta em que o homem corresponde à necessidade de deus e cuida dele. A esse respeito, há uma passagem das Contribuições, na qual Heidegger mostra que o último deus precisa da filosofia (Cf. Ibid., § 259, p. 423). Com essa concepção, Heidegger pretende referir-se ao fato de que a filosofia, enquanto compreensão do ser, representa a premissa para o pensamento e a experiência de deus. Sabe-se, contudo, que a filosofia constitui uma maneira de abrigo da verdade ao lado da arte. De fato, também a arte é um exercício interpretativo por meio do qual a verdade do ser toma forma. É por essa razão que, como se disse, a arte oferece um contato com o divino. Dessa maneira, a passagem citada pode valer igualmente com respeito à arte: o último deus não precisa somente da filosofia, mas também da arte.

Nesse contexto, propusemos designar a relação do homem com o último deus por meio da expressão "transcendência teológica". Dessa relação, os Beiträge destacam em particular o aspecto de cuidado que se realiza na arte e no pensar, assim como nas outras formas de abrigo. Além disso, percebe-se a aversão heideggeriana para a atitude calculadora, na qual deus é objeto de previsão e centro de projeção das expectativas humanas. Lê-se, em contraluz, a valorização implícita do aguardar (Warten), que será indagado sobretudo no texto Para a discussão da serenidade e que indica uma modalidade de abertura ao futuro - abertura que seja livre de expectativa e de tensão voluntária para a meta ${ }^{34}$. Esses aspectos do aguardar enquanto

\footnotetext{
34"Aguardar (warten), pois bem; mas nunca estar em expectativa (erwarten); pois o estar em expectativa prende-se já com uma representação e com o seu objeto representado" (Cf. Id., 2000, p. 43).
} 
espera genuína emergem, contudo, já da reflexão heideggeriana sobre a retenção, a qual consiste num acolher cheio de pudor num aproximar-se não-impositivo que respeita, mantendo-se à distância, a livre manifestação dos fenômenos. Não é por coincidência que a retenção é considerada por Heidegger como a tonalidade afetiva fundamental da relação com o último deus ${ }^{35}$ - O cuidado, o aguardar e a retenção são, portanto, os traços distintivos que delineiam a transcendência teológica dentro do horizonte dos Beiträge.

Com base nas reflexões conduzidas nestas páginas, pode-se fornecer um resumo final da rede de relações que ligam a arte, o afeto fundamental e a transcendência teológica. Em primeiro lugar, ficou evidente a centralidade da Grundstimmung, por meio da qual o artista e os espectadores são diretamente expostos à doação do ser e se deixam envolver pelo seu acontecimento. O choque que acompanha a tonalidade emotiva, despertada pela obra, chamou a atenção para o desdobramento repentino de uma dinâmica de transcendência, na qual os espectadores são trazidos para uma dimensão habitualmente negligenciada nas práticas ônticas. Em virtude da experiência da disposição fundamental, em que o artista cria e à qual os espectadores são reconduzidos, a arte constitui o lugar privilegiado da transcendência ontológica. Mas, precisamente pelo fato de mediar um contato com o ser, a arte delimita o espaço de um possível encontro com o divino. Nesse sentido, ela torna-se, ao mesmo tempo, o lugar e a cena da transcendência teológica, concebida como a relação cuidadosa e não oportunista do homem com a divindade. A arte, precisamente ao abrir espaço para a transcendência ontológica,

35 "A retenção [...] nela afina-se o ser-aí com vistas ao silêncio do passar ao largo do último deus" (Cf. Id., 2015, p. 21). 
torna-se o recinto sagrado - o templum - da transcendência teológica. Mas a arte só pode ser esse lugar de transcendência porque a sua criação e a sua experiência se enraízam na disposição fundamental. Em última análise, é a Grundstimmung, experimentada e ressonante na obra, que se torna mediadora da relação homem-ser e, assim, do relacionamento homem-deus. $\mathrm{O}$ afeto fundamental, precisamente, revela-se como o canal da transcendência ontológica, e, assim, da transcendência teológica. $\mathrm{Na}$ afetividade, explorada e despertada pela arte, realiza-se, afinal, o transcender do homem e, assim, alimenta-se e se perpetua o seu profundo desejo de infinito.

\section{Referências bibliográficas}

ARISTÓteles. Poética. Trad. Eudoro de Sousa. Porto Alegre: Ed. Globo, 1966.

BORGES-DUARTE, I. Arte e técnica em Heidegger. Lisboa: Documenta, 2014.

CAPUTO, A. Pensiero e affettività. Heidegger e le Stimmungen (1889-1928). Milano: Angeli, 2001.

CORIANDO, P.-L. Affektenlehre und Phänomenologie der Stimmungen: Wege einer Ontologie und Ethik des Emotionalen. Frankfurt a.M.: Klostermann, 2002.

HEIDEGGER, M. Phänomenologische Interpretationen zu Aristoteles. Einführung in die phänomenologische Forschung. Gesamtausgabe. v. 61. BRÖCKER, W.; BRÖCKER-OLTMANNS, K. (ed.). Frankfurt a.M.: Klostermann, 1985.

. "Phänomenologische Interpretationen zu Aristoteles. Anzeige der hermeneutischen Situation". Dilthey-Jahrbuch, v. 6, 1989, pp. 235-269.

_-_. Grundbegriffe der aristotelischen Philosophie. Gesam- 
tausgabe. v. 18. MICHALSKI, M. (ed.). Frankfurt a.M.: Klostermann, 2002.

- Ser e tempo. Trad. Marcia Sá Cavalcante Schuback. Petrópolis: Vozes, 2006.

"Fenomenologia e teologia". In: Marcas do caminho. Trad. Enio Paulo Giachini, Ernildo Stein, Marco Antônio Casanova. Petrópolis: Vozes, 2008, pp. 56-88.

. Metaphysische Anfangsgründe der Logik im Ausgang von Leibniz. Gesamtausgabe. v. 26. HELD, K. (ed.). Frankfurt a.M.: Klostermann, 1978.

. A essência do fundamento. Trad. Artur Morão. Lisboa: Edições 70, 1988.

- Os conceitos fundamentais da metafisica. Trad. Marco Antônio Casanova. Rio de Janeiro: Forense Universitária, 2006a.

" "Vom Ursprung des Kunstwerks: Erste Ausarbeitung". HEIDEGGER, H. (ed.). Heidegger Studies, v. 5, pp. 5-22, 1989a.

Kunstwerks"'. HERRMANN, F.-W. von (ed.). Heidegger Studies, v. 6, pp. 5-7, 1990.

. Hinos de Hölderlin. Trad. Lumir Nahodil. Lisboa: Instituto Piaget, 2004.

- A origem da obra de arte. In: Caminhos de Floresta. BORGES-DUARTE, I. (ed.). 2 ed. Lisboa: Fundação Calouste Gulbenkian, 2012, pp. 5-94.

_-_. Beiträge zur Philosophie. Vom Ereignis. Gesamtausgabe. v. 65. HERRMANN, F.-W. von (ed.). Frankfurt a.M.: Klostermann, 1989b.

. Grundfragen der Philosophie. Ausgewählte »Probleme« 
der »Logik«. Gesamtausgabe. v. 45. HERRMANN, F.-W. von (ed.). Frankfurt a.M.: Klostermann, 1984.

- Nietzsche. v. 1. Trad. Marco Antônio Casanova. Rio de Janeiro: Forense Universitária, 2007.

. Logik. Heraklits Lehre vom Logos. In: Heraklit. Gesamtausgabe. v. 55. FRINGS, M. S. (ed.). 2 ed. Frankfurt a.M.: Klostermann, 1987, pp. 183-387.

. "Para a discussão da serenidade. De uma conversa sobre o pensamento, que teve lugar num caminho de campo". In: Serenidade. Trad. Maria Madalena Andrade e Olga Santos. Lisboa: Instituto Piaget, 2000, pp. 29-69.

"...Poeticamente o homem habita...". In: Ensaios e conferências. Trad. Emmanuel Carneiro Leão et. al. Petrópolis: Vozes, 2006b, pp. 5-7.

. "De uma conversa sobre a linguagem entre um japonês e um pensador". In: A caminho da Linguagem. Trad. Marcia Sá Cavalcante Schuback. Petrópolis: Vozes, 2003, pp. 71-120. - Seminários de Zollikon. Trad. Gabriella Arnhold e Maria de Fátima de Almeida Prado. Petrópolis: Vozes, 2001.

. Zum Wesen der Sprache und zur Frage nach der Kunst. Gesamtausgabe. v. 74. REGEHLY, T. (ed.). Frankfurt a.M.: Klostermann, 2010.

HERRMANN, F.-W. Heideggers Philosophie der Kunst. Eine systematische Interpretation der Holzwege-Abhandlung „Der Ursprung des Kunstwerkes?. Frankfurt a.M.: Klostermann, 1994a. . Wege ins Ereignis. Zu Heideggers »Beiträgen zur Philosophie «. Frankfurt a.M.: Klostermann, 1994b.

- Ansatz und Wandlungen der Gottesfrage im Denken Martin Heideggers. In: SIROVÁTKA, J. (ed.). Endlichkeit und Transzendenz: Perspektiven einer Grundbeziehung. Hamburg: 
Meiner, 2012, pp. 153-181.

PASQUALIN, C. "Der 'pathische' Grund des Hermeneutischen:

Die ontologische Priorität der Befindlichkeit vor dem Verstehen". Heidegger Studies, v. 31, 2015, pp. 129-151.

VOLPI, F. "L'etica rimossa di Heidegger". MicroMega, v. 2, 1996, pp. 139-163.

WERLE, M.A. Poesia e pensamento em Hölderlin e Heidegger. São Paulo: Editora Unesp, 2004. 